\title{
A DISPONIBILIDADE (NO EXERCÍCIO) DOS DIREITOS DA PERSONALIDADE COMO DEFERÊNCIA À DIGNIDADE HUMANA NO DIREITO CIVIL CONSTITUCIONALIZADO
}

\author{
THE AVAILABILITY (IN THE EXERCISE) OF THE PERSONALITY RIGHTS LIKE \\ DEFERENCE TO THE HUMAN DIGNITY IN THE CONSTITUTIONALIZED CIVIL LAW
}

\author{
Jorge Renato dos Reis ${ }^{1}$ \\ Iuri Bolesina ${ }^{2}$
}

Data de recebimento: 27/02/2015

Data da aprovação: 10/06/2015

\begin{abstract}
RESUMO
Sob a lógica da constitucionalização do direito privado e através dos aportes da fenomenologia, intenta-se um estudo jurídico e crítico acerca da possiblidade de renúncia total ou parcial do exercício dos direitos da personalidade como deferência à dignidade humana. Assim, no primeiro item realizou-se uma abordagem conceitual e histórica sobre a repersonalização do direito privado. Em seguida, o estudo dedicou-se a elucidar a posição jurídica dos direitos da personalidade no ordenamento legal brasileiro. Por fim, analisou-se criticamente a possibilidade ou não de renúncia total ou parcial do exercício dos direitos da personalidade. Em conclusão, obteve-se, em termos gerais, como acertada a posição que vê na possibilidade de renúncia total ou parcial dos direitos da personalidade efetiva deferência à dignidade humana. Afinal, é a partir da renúncia total ou parcial do exercício de direitos da personalidade que uma pessoa pode ser o que ela é ou pretende ser (livre desenvolvimento da personalidade), sentindo-se bem consigo mesma, e buscar seus projetos de vida. Isto, todavia, merece ressalvas: a disponibilidade do exercício não pode se traduzir em autolesão à dignidade humana, tampouco atrofiamento das singularidades de cada fase do desenvolvimento humano.
\end{abstract}

PALAVRAS-CHAVE: Direito civil constitucionalizado. Direitos da personalidade. Renúncia do exercício. Dignidade humana.

\begin{abstract}
Under the logic of constitutionalization of private law and through the contributions of phenomenology, tries to be a legal and critical study of the possibility of full or partial waiver of the exercise of personal rights in deference to human dignity. Thus, the first item there was a conceptual and historical approach to repersonalization of private law. Then, the study set out to clarify the legal position of the personality rights in the Brazilian legal system. Finally,
\end{abstract}

\footnotetext{
${ }^{1}$ Pós-Doutor pela Università Degli Studi di Salerno-Itália. Doutor pela Universidade do Vale do Rio dos SinosUNISINOS. Mestre em Desenvolvimento Regional pela Universidade de Santa Cruz do Sul-UNISC. Especialista em Direito Privado pela Universidade de Santa Cruz do Sul-UNISC. Graduado em Direito pelas Faculdades Integradas de Santa Cruz do Sul-FISC. Professor e pesquisador do Programa de Pós-Graduação Stricto-Sensu-Mestrado e Doutorado em Direito da UNISC. Professor colaborador da Scuola di Dottorato in Diritto Tulio Ascarelli da Università Degli Studi di Roma TER - Itália. Coordenador do projeto de pesquisa "O direito de autor no constitucionalismo contemporâneo" e do projeto de pesquisa "Intersecções jurídicas entre o público e o privado", vinculados ao CNPq. E-mail: jreis@ viavale.com.br

${ }^{2}$ Doutorando e Mestre em Direito pela Universidade de Santa Cruz do Sul - UNISC. Especialista em Direito Civil pela Faculdade Meridional - IMED. Integrante do Grupo de Pesquisa "Intersecções jurídicas entre o público e o privado", coordenado pelo Pós-Dr. Jorge Renato dos Reis, vinculado ao CNPq. Professor da escola de direito da Faculdade Meridional - IMED. Advogado. E-mail: iuribolesina@ gmail.com
} 
it was examined critically whether or not to waive or partially waive the exercise of personal rights. In conclusion, we obtained, in general terms, as the right position to understand about the possibility of total or partial waiver of the rights of personality in effective deference to human dignity. After all, it is from the complete or partial waiver of the exercise of the personality rights that a person can be what it is or intends to be (free development of personality), feeling good about yourself, and get your life projects. This, however, deserves reservation: the availability of exercise can not be reflected in self-injury to human dignity, either atrophy of the singularities of each stage of human development.

KEYWORDS: Constitutionalized civil law. Personality rights. Waiver of exercise. Human dignity.

\section{INTRODUÇÃO}

Com o advento da Constituição Federal de 1988 e, posteriormente, do Código Civil de 2002, o ordenamento jurídico brasileiro passou por mudanças de perspectiva no seu acontecer. Migrou de uma lógica individual e patrimonialista para uma lógica centrada na pessoa e na dignidade humana. Com efeito, positivaram-se direitos muito caros à pessoa e à sua dignidade, aos quais se denominou direitos da personalidade. Originalmente, tais direitos integravam o rol patrimonial do seu titular e serviam como bases de resistência aos abusos do Estado, dos particulares e do próprio titular destes direitos, abusos que, paradoxalmente, eram assinalados pelo próprio Estado, ou seja, um dos possíveis violadores.

Em face disso, parte dos pesquisadores percebeu que o tratamento que estava sendo dedicado aos direitos da personalidade não se coadunava com as novas perspectivas. Foi nesse momento que se começou a cogitar, em deferência à própria dignidade humana expressada na condição de livre desenvolvimento da personalidade, a possibilidade de renúncia total ou de disponibilidade parcial do exercício dos direitos da personalidade. A hipótese permanece em aberto e é a partir dela que se busca desenvolver o estudo presente.

Dito isso, arquiteta-se a estrutura do presente texto em três eixos. No primeiro, o foco recairá sobre a proteção da dignidade da pessoa humana no e pelo direito privado brasileiro, com ênfase nas disposições do Código Civil, a partir do que se convencionou denominar constitucionalização do direito privado. Nesse ínterim, portanto, almeja-se aclarar questões conectadas à repersonalização do direito privado e às teorias e práticas jurídicas que orbitam determinantemente esta temática.

Na sequência, o segundo espaço do artigo dedicar-se-á a traçar um perfil acerca da posição jurídica dos direitos da personalidade no ordenamento legal brasileiro. Para tanto, centralizar-se-á no tratamento jurídico-legal dos direitos da personalidade, ou seja, nos debates que dizem respeito ao paralelismo que tais direitos possuem com os direitos 
fundamentais e, também, nas celeumas que envolvem a necessidade e utilidade prática entre optar-se por uma cláusula geral de tutela da personalidade ou entre um rol taxativo destes direitos. Vale observar que não se terá a intenção, pelo menos não neste momento, de observar a sua natureza jurídica e caracteres fundantes dos direitos da personalidade.

Ao final, no terceiro item do desenvolvimento do estudo, tencionar-se-á agregar valor à discussão sobre a possibilidade ou não da renúncia ou da disponibilidade parcial do exercício dos direitos da personalidade ou mesmo dos direitos em si, como eventualmente cogita-se na doutrina. Destarte, a partir dos constructos dos dois primeiros itens e com o auxílio de alguns exemplos concretos buscar-se-á imergir no tratamento que o ordenamento jurídico brasileiro dedica a essa questão.

\section{A PROTEÇÃO E A PROMOÇÃO DA DIGNIDADE HUMANA NO/PELO DIREITO PRIVADO CONSTITUCIONALIZADO}

A aceitação da dignidade humana como pilar central da ordem jurídica brasileira deve muito ao processo que se popularizou como "constitucionalização do direito" e, mais especificamente, no espaço do direito privado, como "constitucionalização do direito privado". Em curtas linhas, a constitucionalização do direito privado, no Brasil, ao menos, constitui-se (a) na aplicação direta e constante da Constituição nas relações privadas, (b) na interpretação e (re)leitura dos regramentos de direito civil a partir (e ao concluir) e de acordo com a Constituição, (c) na criação da legislação civil coadunada com a Constituição e, por fim, (d) na inserção de conteúdos outrora infraconstitucionais e da experiência jurisprudencial consolidada no texto constitucional (SARLET, 2008, p. 306).

A alocação da dignidade humana no centro do ordenamento jurídico brasileiro deu-se com a Constituição Federal de 1988 (artigo $1^{\circ}$, III), a qual inaugurou, no documento público e oficial de maior relevância, o pensamento jurídico centrado na dignidade humana. Tal noção, que foi seguida pelo Código Civil de 2002 - todavia, não sem resistência neste âmbito -, trouxe notável transformação no códex que necessitou reformular-se, culminando no cadenciado enfraquecimento do excessivo individualismo e patrimonialismo que pautavam as relações desenvolvidas neste espaço, em prol de uma visão que privilegiasse a dignidade e a pessoa humana.

Esse movimento jurídico consolidou fenômenos que foram resumidos nos títulos "despatrimonialização" e "repersonalização" do direito privado, os quais conduziram a inovações e à positivação de institutos no cenário civil, dentre as quais o reconhecimento da 
solidariedade jurídica (REIS; ZIEMANN, 2013), da boa-fé objetiva (MARTINS-COSTA, 1999), da função social, do patrimônio mínimo (FACHIN, 2006), dentre outros, os quais, em retroalimentação, serviram como mecanismos jurídicos de consolidação da dignidade humana como fundamento do direito privado constitucionalizado. Igualmente, é acertado asseverar que tais fenômenos edificaram os pilares fundacionais do Código Civil de 2002: rigor técnico e lógico, proximidade com as estruturas dos sistemas jurídicos de Portugal, Alemanha e Itália, eticidade, socialidade e operabilidade (TIMM, 2008, p. 53-55).

Nesse contexto, a despatrimonialização e a repersonalização do direito privado servem como matriz que coloca a pessoa humana em primeiro lugar, mas não no sentido clássico liberal burguês presenciado no anos que sucederam a Revolução Francesa (individualismo, atomismo e patrimonialismo ao extremo), e sim numa perspectiva crítica que torna a pessoa humana e sua dignidade o elemento principal do arranjo jurídico e o patrimônio, por seu turno, como coadjuvante (FACHIN, 2003, p. 218). Indo além, é possível afirmar que o grande desafio dos intérpretes do direito privado constitucionalizado é perceber que a pessoa humana passa a ser sujeito de direitos nascidos da dignidade humana e não mais sujeitos do direito, objetos de trabalho do direito, que sob a lógica do patrimonialismo eram tutelados. Em síntese: o patrimônio serve à dignidade e não o inverso (LÔBO, 1999, p. 103).

Outra modificação deveras relevante para o direito privado trazida pela sua constitucionalização é o reconhecimento de uma nova lógica normativa. Agora percebe-se uma clara distinção em grau e gênero entre princípios, direitos fundamentais e regras que, apesar da diferenciação entre si, capitaneados pela dignidade humana conjugam forças para a harmonização e interpretação teológica do sistema jurídico. Ocorre, em síntese, uma circularidade simbiótica entre normogênese e densificação, ou seja, ao tempo que os princípios e/ou os direitos fundamentais dão vida a uma regra, esta regra evidencia em concreto o conteúdo daquele princípio ou direito fundamental que lhe deu razão de ser. De tal forma:

A concepção principiológica do Direito Civil dá margem à revisão dos estatutos clássicos do Direito Civil, repondo o ser humano, e seu ambiente sustentável, no patamar de entes de máxima relevância ao ordenamento jurídico. Com isto se impõe uma releitura cabal das instituições de Direito Privado, ainda arcaicas em face do conservadorismo da dogmática reinante, de caráter patrimonialista. [...] O Código, como qualquer conjunto de regras, deve ser analisado como via concretizadora dos princípios aos quais densifica (ARONNE, 2013, p. 107-108) 
Ao lado disso é preciso dar-se conta de que a norma é fruto da interpretação e não o inverso. Quer-se dizer com isso que as enunciações gramaticais, os textos sob os quais os princípios vêm expressados, quando sem a devida compreensão e, consequentemente, interpretação, não passam disto: texto. Palavra ou frase que pouco diz (GRAU, 2013, p. 16/39). Os textos legais (sejam quais forem) quando interpretados produzem uma norma jurídica. Logo, diferentemente do que sustenta Alexy (2008, p. 51/85), não é a norma que produz um princípio ou uma regra, mas um princípio ou uma regra que, quando interpretado, produz uma norma. Assim, texto e norma são coisas distintas (o que obsta o formalismo objetivista da interpretação), mas não estão separadas e, sim, conectadas (o que obsta o subjetivismo da interpretação) (STRECK, 2012, p. 336).

Em outra seara, o movimento de repersonalização do direito privado, no que tange à aplicação concreta dos institutos do direito privado, notadamente com o reconhecimento dos direitos da personalidade, fez com que o Código Civil de 2002 abandonasse as linhas interpretativas exegetas e liberais oitocentistas, o que culminou numa renovada visão da pessoa humana. Significa dizer, em termos práticos, que cada pessoa humana passa a ser vista como única, dotada de uma singularidade exclusiva, identicamente aos seus semelhantes, também dotados de suas singularidades exclusivas, o que não quer importar em individualismo e insulamento em si mesmo. Destarte, instala-se uma relação paradoxal: de um lado, a pessoa humana é considerada como igual, provida de igual dignidade humana como seus semelhantes e, portanto, titular e carecedora de tratamento isonômico; e, de outro lado, é reconhecida em sua individualidade concreta. Tal paradoxo conduz o direito civil para além das teorizações e previsões legais abstratas, exigindo a sua interpretação nas relações existenciais únicas, ou seja, caso a caso (SILVA FILHO, 2007, p. 2783).

Destacável, por oportuno, que, ao lado do até então exposto, ocorreu a aproximação entre o público e o privado, criando-se espaços de intersecção, bem como a revisão da supremacia do interesse público sobre o interesse privado (SCHIER, 2010, p. 242-243), o que favoreceu o aperfeiçoamento da tutela jurídica da pessoa humana com base em sua autonomia e liberdade com dignidade, relegando a segundo momento tal tutela com base nos interesses ditos públicos. Em sentido oposto, contudo, as intersecções entre o público e o privado criaram alvos de críticas sustentadas, quase que por completo, em questões de cunho econômico e patrimonial, aduzindo-se que é ingênuo tentar controlar o mercado através do direito, dissipando as linhas e caracteres distintivos existentes entre o espaço/interesse público e o espaço/interesse privado (TIMM, 2008, p. 43). Tais críticas, contudo, buscam mascarar a interpretação defasada que utilizam sob a argumentação de que deixar o mercado livre é a 
melhor forma de gerar crescimento econômico para um país e, a partir disto, aumentar os investimentos, a distribuição de renda e o acesso a bens e serviços úteis à dignidade humana. Seria verdade se não fosse falacioso como recentemente demonstrou Piketty (2014, p. 32-35), notadamente em países como o Brasil, em que além dos problemas de (má) distribuição de renda, ainda é necessário lidar com questões crônicas de desequilíbrio de poder, exploração e abuso comercial e corrupção desmedida.

De qualquer sorte, a constitucionalização do direito privado, no que diz respeito à repersonalização do direito civil, trouxe consigo o fortalecimento e a intensificação da aplicação dos direitos fundamentais nas relações privadas, fazendo valer e fazendo-se valer de teorias jurídicas oriundas da teoria dos direitos fundamentais que, aplicadas a casos concretos da vida civil, tornaram-se de bom tom para a adequada repersonalização do direito privado. Dentre essas teorias pode-se citar a força normativa da Constituição (HESSE, 1991), a eficácia irradiante da Constituição ${ }^{3}$ e o dever de proteção aos direitos fundamentais ${ }^{4}$ (CANARIS, 2003), a aplicação direta dos direitos fundamentais nas relações interprivadas, a oxigenação principiológica dos regramentos privados através de "regras gerais de conteúdo aberto" (TEPEDINO, 2007, p. XIX) que refutam o dogma da completude, a hermenêutica filosófica, assim como a releitura dos poderes/deveres da jurisdição constitucional. $\mathrm{O}$ conjunto dessas teorias, quando aplicadas no direito privado, formam o que Perlingieri (2008, p. 1) - um dos mentores do direito civil-constitucional - denomina de pressupostos teóricos da doutrina do direito civil na legalidade Constitucional.

Por evidente que esse movimento teórico de reposição das estruturas fundantes do direito privado não passou imune de críticas de toda ordem. De norte é comum ouvir censuras acerca da "quebra" da segurança jurídica (por consequência da aplicação direta dos direitos fundamentais nas relações privadas), do paternalismo estatal (em face da ingerência do Estado, notadamente do judiciário, em relações contratuais particulares) e também da violação da autonomia da vontade (em vista da concretização da teoria do dever de proteção aos direitos fundamentais envolvidos em contendas privadas) (TIMM, 2008, p. 13-15/43). Devese alertar, porém, que tais críticas erram o objeto de queixa, pois direcionadas equivocadamente aos fenômenos nascidos da constitucionalização, quando, na verdade, deveriam atingir a forma como esses fenômenos são utilizados pelos juristas.

\footnotetext{
${ }^{3}$ Faz-se referência ao emblemático "caso Lüth" (BVerfGE 7, 198).

${ }^{4}$ Faz-se referência aos julgamentos sobre a autorização e regulamentação do aborto (BVerfGE 39, 1 - 1975 e BVerfGE 88, 203 - 1993).
} 
Diante de tal quadro, mais uma vez faz-se pertinente a advertência de Tepedino (2007, p. XV) no sentido de que, provavelmente, o grande desafio seja realizar constantemente uma espécie de autovigia, na qual cada intérprete deve ditar como se deve proceder ao lidar com questões do direito civil constitucionalizado, a fim de não render-se à zona de conforto da interpretação de outrora e aos discursos elegantemente empacotados pelo mercado, visando, como manda a Constituição Federal, atingir o máximo potencial normativo da dignidade humana no direito privado contemporâneo.

\section{A POSIÇÃO JURÍdICA DOS DIREITOS DA PERSONALIDAdE NO ORDENAMENTO BRASILEIRO}

O ponto de partida quando se pretende trabalhar os direitos da personalidade contemporaneamente deve ser sempre a complexidade da pessoa humana, da dignidade humana e do contexto existencial do tempo presente. Isso alerta àqueles que pretendem buscar um conceito definitivo ou neutro de direitos da personalidade, bem como àqueles que visam tipificar um rol exaustivo de direitos da personalidade, para a ingenuidade que tais esforços representariam. Afinal, é fácil perceber como a cada momento novos riscos e desafios surgem à personalidade humana, demandando novos direitos e formas de tutela. De forma introdutória e fugaz, poder-se-ia dizer que os direitos da personalidade são um conjunto de direitos que todos possuem, mas que em cada pessoa possuem uma especificidade distinta, sendo tão próprios de cada qual que por vezes chegam a confundir-se com ele e expressar a sua personalidade a terceiros (BELTRÃO, 2014, p. 10). No Brasil, estariam pacificamente neste conjunto de direitos, por exemplo, a imagem, a integridade psicofísica, a privacidade e a honra.

A concretização dos direitos da personalidade no Brasil, sob a égide do direito repersonalizado pela primazia da dignidade da pessoa humana, iniciou-se com a Constituição Federal de 1988. Sua tutela de modo direto ou conexo aparece de forma mais clara em pelo menos quatro passagens do texto constitucional: no artigo $1^{\circ}$, III, que prevê a dignidade humana como princípio fundamental; no artigo $3^{\circ}$, incisos I e IV, nos quais está disposta a lógica do desenvolvimento livre, isonômico e solidário da personalidade através dos objetivos ali elencados; em praticamente todo artigo $5^{\circ}$, que trata dos direitos fundamentais de primeira dimensão/defesa, possibilitando o livre desenvolvimento da personalidade; e, ao longo de outros direitos fundamentais, esparsamente previstos na Constituição (como nos artigos $6^{\circ}, 7^{\circ}$, 194, 205, 225, 226 e 227, para ficar apenas nestes). 
Vale destacar que o Brasil reconheceu no artigo $1^{\circ}$, III, da Constituição Federal, uma cláusula geral de tutela dos direitos da personalidade, a exemplo do que já se verificava no direito luso (SOUSA, 1995, p. 104-105) e no direito germânico (MIRANDA; RODRIGUES JUNIOR; FRUET, 2012, p. 20-21), por exemplo. A cláusula geral de tutela dos direitos da personalidade, em máximo resumo, pode ser entendida como uma disposição normativa, geralmente de cunho material jusfundamental, que engloba todas as dimensões da personalidade humana em todas as suas perspectivas, no tempo passado, presente e futuro. Como é de se intuir, tal ideia é extremamente sedutora e, ao mesmo tempo, frágil. Sedutora porque possibilita uma abertura material de tutela da dignidade humana, na sua expressão dos direitos da personalidade, viabilizando e potencializando o livre desenvolvimento da personalidade através de direitos tipificados e não tipificados; frágil, pois relega o seu reconhecimento a uma espécie de "boa vontade" - à discricionariedade - estatal, especialmente, do Poder Judiciário que, ao fim e ao cabo, é quem realiza a última salvaguarda jurídica. Logo, padeceria a cláusula geral de tutela da personalidade de um atrofiamento ingênito de suas possibilidades (ALMEIDA, 2012, p. 92-93).

Mencionado atrofiamento ingênito acaba engendrando efeitos concretos no momento da tutela efetiva dos direitos da personalidade. Para ilustrar, basta observar um punhado de decisões jurisdicionais e perceber-se-á que elas, valendo-se dessa discricionariedade, preferem utilizar-se da técnica da ponderação alexyana - à brasileira - (STRECK, 2011, p. 10) ao invés da aplicação da teoria dos círculos concêntricos, apenas por exemplo, a partir das balizas mais claras e racionalmente avaliáveis - que foram traçadas pela Corte Europeia de Direitos Humanos em diversas oportunidades. Igualmente, pode-se verificar que, em torno da cláusula geral de tutela da personalidade, acaba-se indo de um extremo ao outro, tudo "em nome" da Constituição e por meio da discricionariedade. É o caso, por exemplo, de julgadores que literalmente criam direitos da personalidade com base em panprincípios (STRECK, 2012, p. 517), ou então que negam efetivos direitos da personalidade com fundamento na proteção à banalização destes direitos. Se de um lado é verdade que o reconhecimento irrefletido de direitos da personalidade significa banalizá-los, por outro lado e ao mesmo tempo, prender-se a um rol engessado é menosprezar a complexidade da pessoa e da dignidade humana. Assim:

[...] mostra-se insuficiente qualquer construção doutrinária que, tipificando vários direitos da personalidade ou cogitando um único direito geral da personalidade, acaba por limitar a proteção da pessoa à atribuição de poder para salvaguarda meramente ressarcitória, seguindo a lógica dos direitos patrimoniais. Critica-se nesta direção, a elaboração corrente, que concebe a proteção da personalidade aos moldes (ou sob o paradigma) do direito de 
propriedade. A personalidade humana deve ser considerada antes de tudo como um valor jurídico [...] de modo a se proteger eficaz e efetivamente as múltiplas e renovadas situações em que a pessoa venha a se encontrar (TEPEDINO, 2007, p. XXIII).

De qualquer forma, além do alcance material proporcionado pela cláusula geral de tutela dos direitos da personalidade há, ainda, a previsão do $\S 2^{\circ}$, artigo $5^{\circ}$ da Constituição Federal, na qual está a cláusula de abertura e recepção da Constituição aos direitos fundamentais. Tal elemento normativo possibilita que direitos que sejam reconhecidos como fundamentais em sentido material (e não obrigatoriamente em sentido formal) (SARLET, 2010, p. 74) advindos dos tratados internacionais de que o Brasil seja parte e/ou do regime ou princípios constitucionais possam ser anexados ao rol de direitos jusfundamentais tutelados pelo Estado brasileiro. Significa dizer que os direitos da personalidade que também sejam considerados de conteúdo fundamental e que não estejam previstos na legislação brasileira, mas estejam anotados expressa ou implicitamente naquelas hipóteses, passam a integrar a ordem jurídica e a esfera de direitos da personalidade.

Todos esses elementos confluem para a percepção de que a proteção da Constituição brasileira à personalidade humana é bastante ampla, dinâmica e blindada. Sem embargo dessas previsões, o Código Civil de 2002, pioneiramente na história brasileira, tratou de positivar expressamente um rol de direitos da personalidade, ao longo dos artigos 11 a 21, elencando em formulações gerais basicamente o direito à integridade psicofísica (artigos 13 a 15), ao nome e ao pseudônimo (artigos 16 a 19), à imagem (artigo 20) e ao direito à privacidade (artigo 21). Diante disso, se por um lado a tipificação desses direitos apaziguou o debate acerca da existência e possibilidade de tutela destes direitos enquanto direitos subjetivos - celeumas geradas pelas teorias negativistas -, por outro lado alimentou a discussão sobre a aparente perfunctoriedade destas positivações, uma vez que as previsões ali contidas expressamente já apareciam em maior medida na Constituição Federal. Além disso, questionou-se que o trato dos direitos da personalidade como direitos meramente subjetivos os relegaria à qualidade de direitos patrimoniais exclusivamente, o que não se coaduna com a repersonalização do direito privado (DONEDA, 2007, p. 42-44).

Daí porque exige-se, atualmente, uma harmonização do parco rol de direitos da personalidade do Código Civil com as previsões mais amplas da Constituição Federal. Agrega-se, ainda, uma atuação preventiva e repressiva de tutela dos direitos da personalidade, vendo-os como direitos subjetivos, mas ao mesmo tempo como direitos objetivos, possibilitando não apenas o tratamento através das vias da responsabilização e reparação 
(civil ou penal), mas também a partir de ações como políticas públicas e ações/investimentos privados autônomas, impulsionando pautas impostas no aspecto objetivo destes direitos (TEPEDINO, 2007, p. XXV).

A conjugação desses elementos conduz a um cenário que não desmerece a tipificação dos direitos da personalidade do Código Civil, por mais tímida que seja, todavia, deixa evidenciada a existência de um caráter aberto (numerus apertus) destes direitos (BELTRÃO, 2014, p. 59-60), justamente pela harmonização do Código Civil de 2002 com a Constituição Federal (e com as teorias sedimentadas pela constitucionalização do direito privado anteriormente citadas que passam a ser o veículo determinante para a efetivação de tal conexão). Destarte, vê-se como pré-requisito constitucionalmente acertado a leitura conjunta dos artigos 11 a 21, do Código Civil, com o artigos $1^{\circ}$, III e $5^{\circ}$, da Constituição Federal. Não fosse isso, estar-se-ia fadado ao não reconhecimento de novos direitos da personalidade ou, ao menos, ao trabalho hercúleo de demonstrá-los como integrantes do núcleo de um dos direitos já tipificados.

$\mathrm{O}$ atual estado da arte dos direitos da personalidade no Brasil parece dissipar boa parte das questões controvertidas existentes até a repersonalização do direito - como um todo - pela dignidade humana. Nesse sentido, tensões como as que concernem à nomenclatura (direitos da personalidade ou direitos de personalidade), à adequação teórica (direito geral da personalidade ou tutela geral da personalidade), sobre a utilidade efetiva dos direitos da personalidade em espécie e sobre existir ou não um rol taxativo dos direitos da personalidade em espécie, passam a tomar tom de superação. Por outro lado, vale destacar que, ao menos, remanesce (alguma) dissidência teórica relevante acerca da unidade ou da pluralidade dos direitos da personalidade, do seu paralelismo com os direitos fundamentais, da sua banalização enquanto categoria jurídico-histórica (MIRANDA; RODRIGUES JUNIOR; FRUET, 2012, p. 23), bem como sobre a forma de aplicação destes direitos às pessoas coletivas e jurídicas e a viabilidade de renúncia do exercício ou mesmo dos direitos da personalidade em si, no todo em ou em parte.

\section{A DiSPONIBILIDADE RELATIVA E VOLUNTÁRIA (NO EXERCÍCIO) DOS DIREITOS DA PERSONALIDADE COMO DEFERÊNCIA À DIGNIDADE HUMANA}

O tempo presente, marcado por tensões de perspectivas modernas e pós-modernas, facilmente ilustradas pelos paralelos dos destempos engessados do direito frente à fluidez dinâmica das novas tecnologias e mídias, demanda dos juristas uma revisão crítica dos 
conceitos tidos como uníssonos até pouco tempo. Tecnicamente, já a partir da Constituição Federal de 1988 e, posteriormente, com o advento do Código Civil de 2002, os direitos da personalidade deveriam ser lidos sob o viés que privilegia a dignidade humana em detrimento do excessivo patrimonialismo outrora reinante no âmbito do direito privado. Não obstante, há evidente resistência a isso sob argumentos que vão desde razões jurídicas (mais ou menos) vazias até moralismos e fundamentalismos.

Logo, a clássica estrutura dos direitos da personalidade, estendida ao exercício desses direitos $^{5}$, que os via como inatos, absolutos, extrapatrimoniais, intransmissíveis, impenhoráveis, vitalícios, necessários e oponíveis erga omnes (BITTAR, 2008, p. 11), passa, no que diz respeito majoritariamente ao seu exercício, a ser alvo de reconsideração, tendente, se não a viabilidade de uma renúncia total (STANCIOLI, 2010, p. 97), ao menos de uma disponibilidade relativa (CANTALI, 2009, p. 259).

Efetivamente, os exemplos contemporâneos revelam que as bases clássicas dos direitos da personalidade são desafiadas rotineiramente por práticas socialmente aceitas, notese: a plena e voluntária exposição (da imagem, do pensamento, da honra, etc) em redes sociais de toda espécie; a participação voluntária em programas televisivos como Big Brother, Casos de Família e Teste de Fidelidade (que não obstante haja certeza do conteúdo ficto deste último programa, há clara exposição dos atores); a participação em esportes violentos ou perigosos como boxe e Wing Walking; a manipulação genética; a prática de nudismo em praias convencionais ou em protestos; a transformação corporal para saciar o desejo de vaidade ou mesmo buscando adequação físico-identitária, e a lista continua indefinidamente e exponencialmente no contexto globalizado e pós-moderno ${ }^{6}$ (SCHREIBER, 2014, p. 26-27).

Fato é que, em que pese o Código Civil de 2002, em seu artigo 11, venha a expressar que “[...] os direitos da personalidade são intransmissíveis e irrenunciáveis, não podendo o seu exercício sofrer limitação voluntária"; no artigo 13 disponha que "[...] é defeso o ato de disposição do próprio corpo, quando importar diminuição permanente da integridade física,

\footnotetext{
5 "Por um lado, a renúncia ao exercício de um direito da personalidade, no plano valorativo, é a afirmação da autonomia da vontade da pessoa natural. [...] Situação plenamente diversa encontra-se quando uma pessoa perde a titularidade do direito. Neste caso, o direito da personalidade é extirpado, não existindo mais condições de possibilidade para seu exercício. [...] a ratio de ambos os casos é muito diversa. Além disso, na renúncia ao exercício, a personalidade jurídica do agente fica intacta, enquanto na renúncia à titularidade, há uma afetação da personalidade da pessoa natural" (STANCIOLI, 2010, p. 98-99).

6 "Se tentarmos prolongar a reflexão sobre a globalização em termos de pensamento jurídico, nos depararemos com a problemática do pós-modernismo em direito. $\mathrm{O}$ fato de que as duas problemáticas não sejam frequentemente associadas deve-se simplesmente ao fato de que elas parecem dizer respeito a comunidades científicas diferentes: a globalização seria preferencialmente assunto dos economistas e dos cientistas políticos, enquanto que o pós-modernismo diria respeito, ao contrário, aos filósofos, e até mesmo aos sociólogos. Eu estimo, no meu entender, como jurista, que os problemas suscitados por uma e por outra possuem aspectos que se relaciona intimamente" (ARNAUD, 1999, p. 195-196).
} 
ou contrariar os bons costumes"; e ao longo dos artigos 11 e 21 traga previsões de várias ordens que vedam total ou parcialmente a limitação voluntária dos direitos de personalidade, a disponibilidade relativa e voluntária dos direitos da personalidade no seu exercício é o que pauta as atuais relações entre sociedade e direito. Em outros termos, seus caracteres distintivos clássicos são postos à prova em situações concretas que aclaram a relatividade, a patrimonialidade, a transmissibilidade, a penhorabilidade, a temporalidade, a limitabilidade e a facultatividade no exercício voluntário destes direitos (CANTALI, 2009, p. 255-256). Isso, porém, a partir de uma leitura civil constitucionalizada, tem menos a ver com interesses patrimoniais e mais a ver com a satisfação dos desejos de transformação e ratificação da personalidade.

Isso porque, contemporaneamente, tem-se uma leitura da autonomia da vontade distanciada do "atomismo" e da sua subserviência à ordem pública já que, ao revés, passa aquela a ser elemento constitutivo desta. Nessa coerência, o direito à renúncia e/ou à disponibilidade relativa voluntária dos direitos da personalidade é efetiva expressão da autonomia da vontade em prol do livre desenvolvimento da personalidade, já que o potencial criativo e transformativo do ser humano sobre si próprio é sempre um projeto inacabado e em constante construção (STANCIOLI, 2010, p. 109/124). Serviriam, assim, a renúncia e/ou a disponibilidade relativa e voluntária dos direitos da personalidade como promotores do livre desenvolvimento da personalidade (já que este dependeria daqueles).

Em termos mais rasos, é a partir da renúncia total ou parcial do exercício de direitos da personalidade que uma pessoa pode ser o que ela é ou pretende ser (livre desenvolvimento da personalidade), sentindo-se bem consigo mesma, e buscar seus projetos de vida, por mais estranhos que possam parecer, mas que, todavia, não se configurem em autolesão à dignidade humana, observadas as singularidades de cada fase do desenvolvimento humano (como, por exemplo, o trabalho artístico infanto-juvenil sobrecarregado e glamurizado em comparação com o trabalho artístico adulto em mesmas situações). Aliás, o célebre caso francês do lançamento dos anões poderia ter um desfecho distinto se analisado em um cenário de direito civil constitucionalizado, afinal, seria incoerente tolerar violentas batalhas de MMA ou a objetificação da mulher em programas como Pânico na Band e, ao mesmo tempo, proibir alguém, devidamente protegido, de ser lançado como bola de boliche (SCHREIBER, 2014, p. 1-2/28). Aliás, mencionado programa televisivo possui em um de seus quadros algo semelhante ao lançamento de anões, só que em uma versão "melhorada": com anões e panicats. 
Por outro lado, há quem sustente que isso passa a ser uma "adulteração" dos direitos da personalidade, pois deixam de ser vistos como instrumentos de defesa para ser vistos como expressões da onipotência e da atomização do indivíduo sobre o eu - com efeitos sobre o nós - (CAMPOS, 2004, p. 151). Tal afirmação, se em sentido histórico-sociológico goza de (in)certa aceitação, por outro lado deve ser recebida com ressalvas no campo jurídico, uma vez que a teoria crítica e especializada nos direitos fundamentais há muito tempo já sinalizou o caráter multidimensional, multifuncional e limitado desses direitos, ou seja, aqueles direitos da personalidade que também são tidos como direitos fundamentais são multidimensionais, multifuncionais e limitados, servindo tanto para a defesa quanto para a promoção da dignidade humana em todas as esferas (SARLET, 2010, p. 45-51). Logo, se os direitos fundamentais que consistem em expressões máximas dos direitos em um Estado contam com essas características, é razoável ponderar que direitos não-fundamentais sofram essas e outras limitações, de forma que os direitos da personalidade que não são fundamentais também são multidimensionais, multifuncionais e limitados, pelo menos.

Assim, se em uma interpretação inadvertida pode-se fazer parecer que as relatadas práticas sociais são "contra legem", uma leitura constitucionalizada dessas condutas tende a conduzir para a sua adequação e licitude - sempre que não violarem a pedra angular que é a dignidade humana neste contexto -. Note-se, inicialmente, que a interpretação constitucional dos artigos 11 e 13 (especificamente) do Código Civil deve deferência ao princípio da dignidade da pessoa humana (art. 1, III, da $\mathrm{CF} / 88$ ) de modo geral e, ao princípio daí adstrito do livre desenvolvimento da personalidade de forma específica (ALMEIDA, 2012, p. 77). Costuma-se dizer que o livre desenvolvimento da personalidade iluminado pela dignidade humana conjuga ainda o ideal de liberdade como autonomia e viabiliza que a pessoa exercite o(s) seu(s) projeto(s) de vida no tempo passado, presente e futuro (STANCIOLI, 2010, p. 124), especialmente em termos de identidade(s) (pessoal, étnica, de gênero, cultural, nacional, etc) (SOUSA, 1995, p. 245-246; CHOERI, 2010, p. 6).

Seguindo essa pista, uma interpretação alinhada com a Constituição Federal foi buscada nas Jornadas de Direito Civil (capitaneadas pelo Superior Tribunal de Justiça e pelo Conselho da Justiça Federal), as quais previram em relação aos artigos 11 a 21 do Código Civil vigente a possibilidade de autolimitação do exercício dos direitos da personalidade, valorizando em medida considerável a autonomia privada e assinalando, porém, critérios abstratos e genéricos como "ordem pública", "boa-fé" e "bons costumes", a fim de possibilitar ao intérprete uma verificação mais pontual em cada caso concreto (CJF, 2012). 
É preciso reconhecer o avanço obtido nos esforços empenhados nas Jornadas de Direito Civil, uma vez que aliviou os direitos da personalidade de parte da carga moral, patrimonial e paternalista com que eram tratados na legislação e prestigiou a liberdade como autonomia digna. Todavia, é igualmente necessário sublinhar pontos que não foram objetos de uma crítica mais contundente e, justamente por isso, permaneceram emperrando a devida tutela constitucionalizada dos direitos da personalidade.

Primeiro, note-se que se reforçou a discricionariedade judicial na resolução das controvérsias no exercício dos direitos da personalidade ao se apostar, sem balizas mais claras, em constructos teóricos como "ponderação" e em termos mais ou menos vagos como "abuso de direito" e "boa-fé objetiva" que, como bem se sabe, são vistos pelo senso comum como disposições que alargam o espectro de interpretação judicial quase que indefinidamente (STRECK, 2012, p. 221). Isso torna hercúlea a tarefa de contradizer o julgador com sucesso (ainda que a argumentação em sentido contrário à do julgador seja de simples elaboração) já que sua interpretação sempre será “em nome” da ponderação e da dignidade humana. Como já se disse em outra oportunidade, continua-se na iminência do uso performativo dos princípios, direitos fundamentais e cláusulas gerais de conteúdo aberto por parte (da vontade) do julgador (REIS; BOLESINA, 2014, p. 11).

Segundo, esses mesmos critérios abertos - boa-fé objetiva, bons costumes, abuso de direito (inclua-se também função social e solidariedade) - tendem a causar sérias dificuldades teóricas e práticas pois trazem percepções imprecisas e, não raro, afirmações vagas no caso concreto, que podem ser motivadas à influência de noções também vagas e imprecisas sobre tecnologia, ciência, religião, moral, justiça, etc (SCHREIBER, 2014, p. 34). Em outros termos, é fácil notar que o exercício dos direitos da personalidade acontece em cenários corriqueiros da vida que, em tese, não deveriam ser solucionados pelo direito como primeira opção (mas sim pela educação ou psicologia ou medicina, etc) e que, justamente por isso, contam com efêmeros e/ou mórbidos traços legislativos ou jurisdicionais para sua solução (como, por exemplo, "bons costumes"), os quais, ao fim e ao cabo, alimentam o Caos no sistema jurídico (ARONNE, 2006, p. 24) ${ }^{7}$.

Sintetizando, o que se tem hoje são antípodas que, paradoxalmente, convivem em um único ambiente. Ao mesmo tempo em que se reconhece que o livre desenvolvimento da

\footnotetext{
7 “[...] a palavra final sobre a sanidade ou paternidade de alguém, pode não vir de um médico nem de um geneticista. Pode vir de um juiz. Pode contrariar integramente a conclusão de um laudo. Seu preço? Um bom fundamento. Razão. Racionalidade. Seu meio? Sistema e discurso. Remédio? Recursos. Trajetória? Caótica. Medo? Indeterminação. Instabilidade. Alguém gostaria que fosse diferente? A história responde. [...] Medo? Vertigem? Não. Caos." (ARONNE, 2006, p. 24).
} 
personalidade carece, para ser pleno, de maior liberdade (maior autonomia da vontade), a qual muitas vezes será contramajoritária e contracultural, amarra-se tal possibilidade a critérios nubilosos à disposição do intérprete e, eventualmente, do poder majoritário e cultural posto (do discurso de/do poder) (CAMPOS, 2004, p. 154). O próprio Perlingieri (1999, p. 162) já advertia que não cabe ao direito civil constitucionalizado tolher qualquer "função expressiva de uma verdade diversa e anticonformista, às vezes destinada a se tornar a verdade de amanhã”, pois, se assim o fizer, torna-se incerta e distante a aprovação legal de questões como multiparentalidade, multimatrimônio, aborto, manipulação genética, regulamentação das drogas e da prostituição, liberdades civis de gênero e transhumanismo, para ficar apenas nestas.

De qualquer forma a cautela é sempre bem-vinda, pois, se de um lado é imperioso repensar a renúncia e/ou a disponibilidade relativa dos direitos da personalidade no seu exercício com vistas ao respeito e à promoção da autodeterminação, da autonomia da vontade, do livre desenvolvimento da personalidade e da dignidade humana, por outro lado carece-se estar atento aos limites destas disposições e renúncias com base na dignidade humana. Não seria de bom tom, contudo, seguir apostando em critérios vagos e carregados de sentido (negativo) cultural e historicamente atribuído como "bons costumes" e "ordem pública" ou em interpretações desconectadas com o direito civil constitucionalizado de institutos válidos como "boa-fé objetiva" e "abuso de direito" (CANTALI, 2009, p. 256-258). Ademais, é válido atentar para a crescente tensão entre liberdade no manejo dos direitos da personalidade e o risco de mercantilização desses direitos, o que culminaria na "coisificação" da pessoa humana (SANDEL, 2013, p. 9-20).

\section{CONCLUSÃO}

A constitucionalização do direito no Brasil, a partir da Constituição Federal de 1988, marcou oficialmente o início de um novo paradigma jurídico centrado na dignidade da pessoa humana. Seguindo essa pista, o Código Civil de 2002 pretendeu albergar o máximo respeito da dignidade humana e, para tanto, além de reformular-se em suas disposições normativas, dedicou-se a uma revisão na sua interpretação. Esse movimento foi iniciado pelo fenômeno da constitucionalização do direito privado e culminou na despatrimonialização e repersonalização do direito privado, ou seja, a pessoa humana e sua dignidade são o elemento central e principal de do direito privado contemporâneo, passando o patrimônio e a lógica patrimonialista a ser subsidiária e sempre deferente aos desideratos da dignidade humana. 
No embalo da constitucionalização do direito privado, o Código Civil de 2002 inovou ao tipificar direitos da personalidade ao longos dos artigos 11 a 21. Apesar de a novidade ter sido recebida como algo positivo, não passou imune de críticas, já que aparentou ser reducionista em relação às previsões da Constituição Federal. Por outro lado, elogiou-se, em parte, a iniciativa de tentar tipificar um rol aberto de direitos da personalidade, pois isso facultava maior certeza no tratamento jurídico desta categoria do que a cláusula geral de tutela dos direitos da personalidade contida no artigo $1^{\circ}$, III, da Constituição.

Nesse contexto, porém, as tensões concretas entre as lógicas modernas e pósmodernas evidenciam práticas sociais que desafiam tanto a tipificação expressa dos direitos da personalidade quanto o tratamento via cláusula geral de tutela. A cada momento novos riscos à personalidade humana aparecem e demandam novos direitos da personalidade para seu tratamento ou, ao menos, novas perspectivas dos direitos da personalidade já reconhecidos.

Contemporaneamente e a partir da repersonalização do direito privado, cogita-se a possibilidade de renúncia total ou de disponibilidade parcial do exercício dos direitos da personalidade. Destaca-se que tal possiblidade é própria do exercício destes direitos e não deles em si. Juridicamente, no Brasil, tais direitos não são passíveis de serem elididos (em situações normais), muito embora o seu não-exercício pelo titular possa ter efeitos aproximados à destruição.

De qualquer sorte, entende-se como acertada a posição que vê na possibilidade de renúncia total ou parcial dos direitos da personalidade efetiva deferência à dignidade humana. Afinal, é a partir da renúncia total ou parcial do exercício de direitos da personalidade que uma pessoa pode ser o que ela é ou pretende ser (livre desenvolvimento da personalidade), sentindo-se bem consigo mesma, e buscar seus projetos de vida. Isso, todavia, merece ressalvas: a disponibilidade do exercício não pode traduzir-se em autolesão à dignidade humana, tampouco atrofiamento das singularidades de cada fase do desenvolvimento humano. Efetivamente, há uma linha tênue entre as ações que dizem respeito ao livre desenvolvimento da personalidade e a autolesão à personalidade - como se viu dos exemplos acima indicados , que demandam adequada interpretação civil-constitucionalizada

\section{REFERÊNCIAS}

ALEXY, Robert. Teoria dos direitos fundamentais. São Paulo: Malheiros, 2008. 
ALMEIDA, Kellyne Laís Laburú Alencar de. O direito ao libre desenvolvimento da personalidade - perspectiva do direito português. In: MIRANDA, Jorge; RODRIGUES JÚNIOR, Otávio Luiz; FRUET, Gustavo Bonato (Orgs.), Direitos da personalidade. 3. ed. São Paulo: Atlas, pp. 65-107, 2012.

ARNAUD, André-Jean. $O$ direito entre modernidade e globalização: lições de filosofia do direito e do Estado. Tradução de Patrice Charles Wuillaume. Rio de Janeiro: Renovar, 1999.

ARONNE, Ricardo. Direito civil-constitucional e teoria do caos: estudos preliminares. Porto Alegre: Livraria do Advogado, 2006.

Sistema Jurídico e Unidade Axiológica. Os Contornos Metodológicos do Direito Civil Constitucional. In: Revista do Instituto do Direito Brasileiro, v. 01, pp. 73-114, 2013.

BELTRÃO, Silvio Romero. Direitos da personalidade. 2. ed. São Paulo: Atlas, 2014.

BITTAR, Carlos Alberto. Direitos da personalidade. 7. ed. Rio de Janeiro: Forense Universitária, 2008.

BRASIL. Código Civil de 2002. Disponível em: http://www.planalto.gov.br/ccivil_03/leis/2002/L10406.htm. Acesso em: 20 jan. 2015.

Constituição Federal de 1988. Disponível em: http://www.planalto.gov.br/ccivil_03/constituicao/constitui\%C3\%A7ao.htm. Acesso em: 20 jan. 2015.

CAMPOS, Diogo José Paredes Leite de. Nós: estudos sobre o direito das pessoas. Coimbra: Almedina, 2004.

CANARIS, Claus-Wihelm. Direitos Fundamentais e Direito Privado Tradução de Ingo Wolfgang Sarlet e Paulo Mota Pinto. Coimbra: Almedina, 2003.

CANTALI, Fernanda Borghetti. Direitos da personalidade: disponibilidade relativa, autonomia privada e dignidade humana. Porto Alegre: Livraria do Advogado, 2009.

CHOERI, Raul Cleber da Silva. $O$ direito à identidade na perspectiva civil-constitucional. Rio de Janeiro: Renovar, 2010.

CJF (Conselho da Justiça Federal). Jornadas de Direito Civil: I, III, IV e V: enunciados aprovados. $2012 . \quad$ Disponível em: <http://www.stj.jus.br/publicacaoinstitucional/index.php/jornada/issue/current>. Acesso em: 20 de jan. 2015.

DONEDA, Danilo. Os direitos da personalidade no novo código civil. In: TEPEDINO, Gustavo. (coord.), A parte geral do novo código civil: estudos na perspectiva civilconstitucional. 3. ed. Rio de Janeiro: Renovar, pp. 35-60, 2007.

FACHIN, Luiz Edson. Estatuto jurídico do patrimônio mínimo. 2 ed. Rio de Janeiro: Renovar. 2006. 
FACHIN, Luiz Edson. Teoria Crítica do Direito Civil. Rio de Janeiro: Renovar, 2003.

GRAU, Eros Roberto. Por que tenho medo dos juízes: a interpretação/aplicação do direito e os princípios. 6 ed. São Paulo: Malheiros, 2013.

HESSE, Konrad. A força normativa da constituição. Tradução de Gilmar Ferreira Mendes. Porto Alegre: Sergio Antonio Fabris, 1991.

IRTI, Natalino, L'età dela decodificazione. 4 ed. Milano: Giuffrè, 1999.

LÔBO, Paulo. Constitucionalização do direito civil. In: Revista de Informação Legislativa, Brasília, v. 141, 1999, p. 99-109.

MARTINS-COSTA, Judith. A boa-fé no direito privado. São Paulo: RT, 1999.

MIRANDA, Jorge; RODRIGUES JÚNIOR, Otávio Luiz; FRUET, Gustavo Bonato. Principais problemas dos direitos da personalidade e estado-da-arte da matéria no direito comparado. In: MIRANDA, Jorge; RODRIGUES JÚNIOR, Otávio Luiz; FRUET, Gustavo Bonato (Orgs.), Direitos da personalidade. 3. ed. São Paulo: Atlas, pp. 1-24, 2012.

PERLINGIERI, Pietro. A doutrina do direito civil na legalidade constitucional. In: TEPEDINO, Gustavo (org.) Direito civil contemporâneo: novos problemas à luz da legalidade constitucional. São Paulo: Atlas, pp. 1-11, 2008.

Renovar, 1999.

Perfis do direito civil: introdução ao direito civil constitucional. Rio de Janeiro:

PIKETTY, Thomas. O capital: no século XXI. Rio de Janeiro: Intrínseca, 2014.

REIS, Jorge Renato dos; ZIEMANN, Aneline. Constitucionalismo Contemporâneo e Princípio da Solidariedade: intersecções jurídicas. In: Anais do X Seminário Internacional Demandas Sociais e Políticas Públicas na Sociedade Contemporânea e VI Mostra de Trabalhos Jurídicos Científicos, Santa Cruz do Sul, 2013.

REIS, Jorge Renato dos; BOLESINA, Iuri. O princípio constitucional da solidariedade no âmbito do direito civil constitucionalizado e a sua aplicação (performativa?) pelo Tribunal de Justiça do Rio Grande do Sul. 2014. Texto inédito.

SARLET, Ingo Wolfgang. A eficácia dos direitos fundamentais: uma teoria geral dos direitos fundamentais na perspectiva constitucional. 10 ed. Porto Alegre: Livraria do Advogado, 2010.

Breves notas sobre a contribuição dos princípios para a renovação da jurisprudência brasileira. In: TEPEDINO, Gustavo (org.) Direito civil contemporâneo: novos problemas à luz da legalidade constitucional. São Paulo: Atlas, pp. 296-310, 2008.

SCHIER, Paulo Ricardo. Ensaio sobre a supremacia do interesse público sobre o privado e o regime jurídico dos direitos fundamentais. In: SARMENTO, Daniel. (org.) Interesses públicos versus interesses privados: desconstruindo o princípio de supremacia do interesse público. Rio de Janeiro: Lumen Juris, 2010, p. 242-243. 
SCHWABE, Jürgen (Coletânea original); MARTINS, Leonardo (Organização e Introdução). Cinqüenta anos de Jurisprudência do Tribunal Constitucional Federal Alemão. Tradução: Beatriz Henning, Leonardo Martins, Mariana Bigelli de Carvalho, Tereza Maria de Castro, Vivianne Geraldes Ferreira. Uruguai: Konrad-Adenauer Stiftung,

SILVA FILHO, José Carlos Moreira da; SILVA FILHO, José Carlos Moreira da. A Repersonalização do Direito Civil em uma sociedade de indivíduos: o exemplo da questão indígena no Brasil. In: XVI Encontro Nacional do Conselho Nacional de Pesquisa e PósGraduação em Direito - CONPEDI, 2007, Belo Horizonte-MG. Anais do XVI XVI Encontro Nacional do CONPEDI. Florianópolis-SC: Fundação Boiteux, 2007. v. 1. p. 2769-2789.

SANDEL, Michael J. O que o dinheiro não compra: os limites morais do mercado. Trad. Clóvis Marques. Rio de Janeiro: Civilização Brasileira, 2013.

SCHREIBER, Anderson. Direitos da personalidade. 3. ed. São Paulo: Atlas, 2014.

SOUSA; Rabindranath V. A. Capelo de. Direito geral de personalidade. Coimbra: Coimbra, 1995.

STANCIOLI, Brunello. Renúncia ao exercício de direitos da personalidade. Belo Horizonte: Del Rey, 2010.

STRECK, Lenio Luiz. Verdade e consenso: Constituição, hermenêutica e teorias discursivas. 4 ed. São Paulo: Saraiva, 2012.

As recepções teóricas inadequadas em terrae brasilis. In: Revista de Direitos Fundamentais e Democracia, Curitiba, v. 10, n. 10, p. 2-37, jul./dez. 2011.

TEPEDINO, Gustavo. Introdução: crise de fontes normativas e técnica legislativa na parte geral do Código Civil de 2002. In: TEPEDINO, Gustavo. (coord.), A parte geral do novo código civil: estudos na perspectiva civil-constitucional. 3. ed. Rio de Janeiro: Renovar, pp. XV-XXXIII, 2007.

TIMM, Luciano Benetti. O novo direito civil: ensaios sobre o mercado, a reprivatização do direito civil e a privatização do direito público. Porto Alegre: Livraria do Advogado, 2008. 